\title{
VISITA DE PROFESSORES E ESTUDANTES ARGENTINOS A FACULDADE DE DIREITO
}

A 26 de julho do corrente ano, teve a Faculdade de Direito occasião de receber a visita da caravana de professores e estudantes argentinos que esteve em São Paulo. Compunha-se a embaixada dos professores Enrique Martinez Paz, decano e catedrático de filosofia da Faculdade de Direito da Universidade Nacional de Córdoba; e Victor N. Romero Del Prado, catedrático de direito internacional privado da referida escola; e dos acadêmicos Hector Lucero, Ricardo A. Gianola, Pablo R. Chiavassa, Alfredo Abarca, Maria T. M. de Morini, Lelio Morini, Roberto J. Sierra, Carlos A. Almuni, Pablo Mariano Videla, Carlos Maldonado, Alberto Carranza, Eduardo Rivota, Eduardo A. Palacio, Abraham Succaria e Benito Machiavelli.

Em sessão solene, a que presidiu o professor Spencer Vampré, diretor da Faculdade de Direito, foram os ilustres professores argentinos recebidos pela congregação, após a visita de cordialidade. Achavam-se presentes, tambem, os representantes do govêrno do Estado, o professor Lúcio Martins Rodrigues, reitor da Universidade de São Paulo, o sr. Consul da República Argentina e numerosas pessoas de destaque nos meios sociais e intelectuais paulistas.

Falou saudando os visitantes em nome da Congregação, o profesor Waldemar Ferreira.

Dirigindo-se aos professores universitários argentinos, disse o professor Waldemar Ferreira do agrado com que recebera a missão de saudá-los em nome dos seus colegas da Faculdade de Direito de São Paulo. Recebera-a envaidecido, pois com um e outro mantinha, de ha muito, as mais afetuosas relações, que o intercâmbio de trabalhos jurídicos aumentava. Se, ha dias, tivera o prazer de apertar, pela primeira vez, a mão de Enrique Martinez Paz, decâno da Faculdade de Direito e Ciências Sociais da Universidade Nacional de Córdoba, datava de dez anos o seu conhecimento com Victor N. Romero Del Prado, catedrático daquela trisecular Universidade. Havia, de resto, duas circunstâncias, que sobremodo o emocionavam ao prestar sua homenagem aos dois exímios professores. Uma era a de que a gloriosa Universidade de Córdoba tinha sido fundada por um bispo, nascido em terras brasileiras. D. Fernando de Trejo y Sinabria era catarinense, de São Francisco. Outra a de ter sido 
ela a formadora do espirito de Dalmacio Velez Sarsfield, o grande codificador argentino, que se abeberou nos monumentais trabalhos de Augusto Teixeira de Freitas, que ele considerava êmulo de Savigny, ao elaborar o codigo civil argentino. Acrescia, ainda, que os dois professores argentinos eram propugnadores do estreitamento maior da amizade entre, as duas maiores nações sulamericanas. Tanto assim que um e outro ali se achavam, Romero Del Prado pela segunda vez, a primeira por ocasião do centenário da lei de fundação dos cursos jurídicos de São Paulo e de Olinda, em 1927; e Martinez Paz o comemorou escrevendo um magnífico trabalho - Freitas y su influencia sobre el Código Civil Argentino, que por aquela ocasião se publicou dedicando-a aos juristas brasileiros como expressão de solidariedade espiritual. Com esses titulos, bem mereciam eles a homenagem que, com tanto afeto, se lhes prestava.

Depois de fazer uma súmula da vida cultural e universitária dos dois professores e de salientar o papel que a Faculdade de Direito de Córdoba tem desempenhado na evolução do pensamento e da formação jurídica da República Argentina, fazendo-lhes ver que outro não foi o papel da Faculdade de Direito de São Paulo na evolução do pensamento e da formação juridica do Brasil, dirigiu-se aos moços universitários argentinos, que ali se achavam, dirigindolhes, tambem, uma saudação entusiástica e carinhosa e formulando votos por que, fieis aos ensinamentos de seus grandes mestres, arcassem com a responsabilidade de manter e aumentar o patrimônio moral e intelectual, que era o apanágio da grande e livre democracia sulamericana, em busca de seus gloriosos destinos.

Em seguida, teve a palavra o bacharelando Auro Soares de Andrade que, como orador oficial do Centro Acadêmico XI de Agosto, exaltou a confraternidade argentino-brasileira e saudou os professores visitantes em nome da mocidade acadêmica de São Paulo. E, por parte dos estudantes argentinos, falou o acadêmico Hector Escuchero.

Assomando, entre aplausos, á tribuna, o professor Enrique Martinez Paz produziu notavel conferência sobre a influência cultural dos jurisconsultos brasileiros na formação das leis e dos códigos argentinos. Relembrou, ainda, a sua atuação no sentido de mais forte aproximação entre o Brasil e a República Argentina.

Por fim usou da palavra o professor Romero N. Del Prado que traçou, em rápidos conceitos, o quadro da ação pacificadora da diplomacia brasileira, na política e nas relações internacionais americanas, desde $o$ tratado de Madrid, devido ao paulista Alexandre de Gusmão, que fixou as fronteiras entre a América portuguesa e a América espanhola, até a recente questão do Chaco, cuja solução foi devida, principalmente, ao tacto e á prudência dos diplomatas brasileiros. 


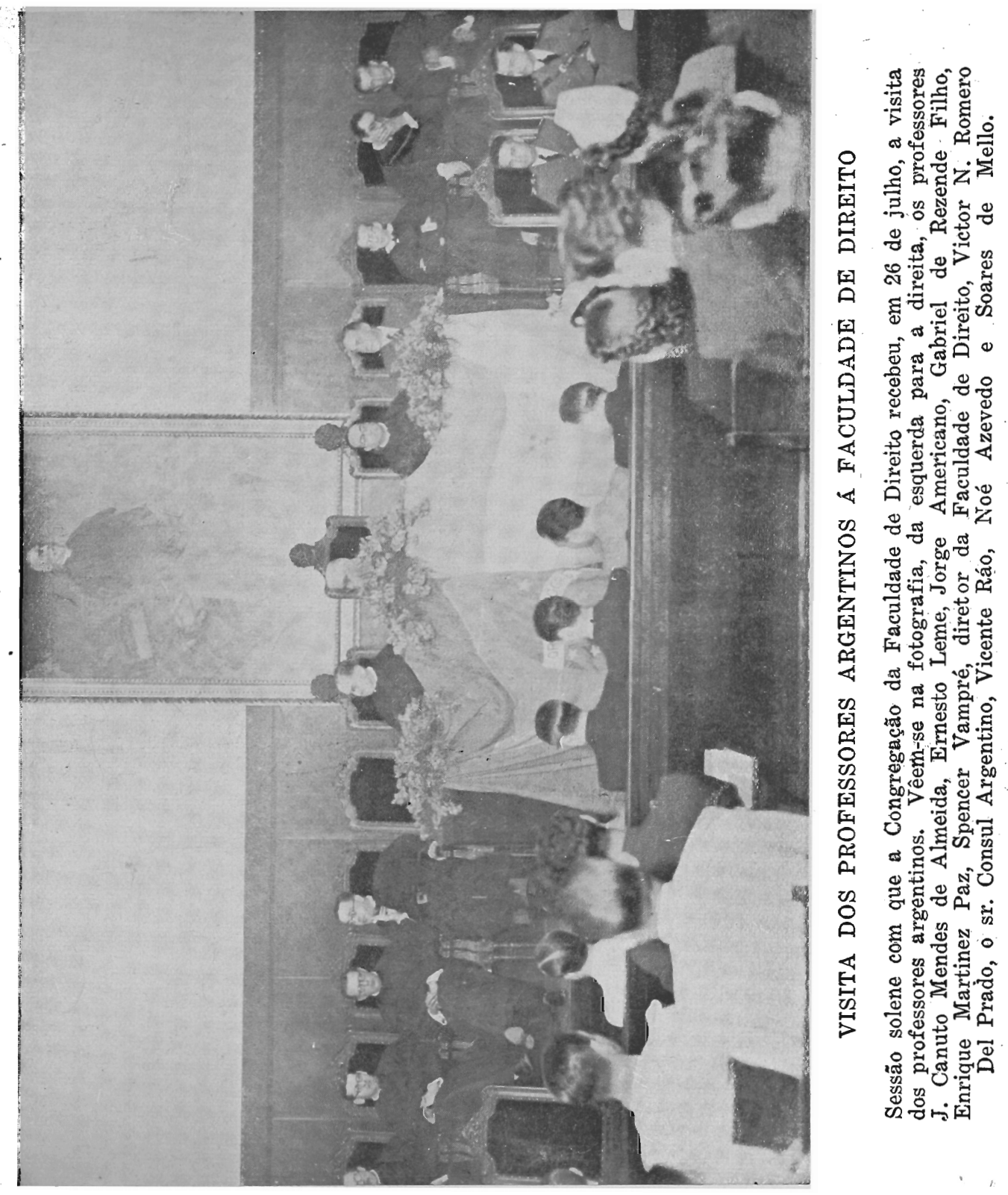

